\title{
Analisis Sistem Jaringan Perpipaan Penyalur Air Limbah (Studi Kasus: Proyek Pengembangan Sistem Saluran Air Limbah Di Pulau Batam Tahap I Kecamatan Batam Kota)
}

\author{
Harry Kurniawan ${ }^{1}$, Imam Setiyohadi ${ }^{2}$, Rizman Hidayat $^{3}$ \\ ${ }_{1,2,3}$ Universitas Riau Kepulauan, Batam,Kepulauan Riau \\ Surel: ${ }^{1}$ harry@ft.unrika.ac.id, ${ }^{2}$ imam.cahaya90@yahoo.com, ${ }^{3}$ rizmanh13@gmail.com
}

\section{ABSTRAK}

Sebagai kota yang memanfaatkan air waduk sebagai air baku untuk air minum, hal ini sangat merugikan karena mengingat sumber air baku Kota Batam sebanyak $70 \%$ berasal dari waduk Duriangkang menurut Kepala Bidang pengelolaan air dan limbah BP Batam. Untuk mengatasi masalah tersebut, BP Batam tengah mengembangkan sistem pengolahan air limbah melalui Proyek Pengembangan Sistem Saluran Air Limbah di Pulau Batam yang terdiri dari 7 tahap dimana pada tahap pertama ini dibangun di kecamatan Batam Kota. Instalasi Pengelolaan Air Limbah (IPAL) (Waste Water Treatment Plant) adalah suatu struktur yang dirancang untuk mengelola dan mengolah limbah biologis dan kimiawi dari air sehingga memungkinkan air tersebut dapat memenuhi standar baku mutu air. Dalam pembangunan proyek tersebut, timbul beberapa pertanyaan pada jaringan perpipaan, salah satunya adalah penyumbatan pada saluran pipa yang disebabkan oleh sampah yang dibuang ke dalam toilet dan kecepatan aliran air limbah yang tidak memenuhi syarat kecepatan minimum. Oleh sebab itu, perlu dilakukan analisis terhadap kecepatan aliran air limbah, kedalaman berenang air limbah dan debit timbulan air limbah untuk mengetahui kemampuan masing-masing pipa utama dalam mengalirkan air limbah menuju IPAL dan permasalahan lainnya.Dari hasil perhitungan hidrolika pada sistem perpipaan pada proyek ini diperoleh nilai sebagai berikut: pada zona A1-1 nilai dari debit total yang didapat adalah 0,350418 $\mathrm{m}^{3} /$ detik, dengan slope $0,3 \%$ dibutuhkan diameter pipa $700 \mathrm{~mm}$ berdasarkan nomogram manning. Dan pada zona A2-1 nilai hasil dari debit total adalah $0,4629445 \mathrm{~m}^{3} /$ detik, dengan slope $0,3 \%$ diperoleh diameter pipa pada zona ini sebesar $700 \mathrm{~mm}$ dari nomogram manning.

\section{Kata kunci}

Air Limbah,

Debit,

Diameter Pipa.

\section{PENDAHULUAN}

Dengan adanya Proyek Pengembangan Sistem Saluran Air Limbah di Pulau Batam. Limbah domestik dan non domestik tidak akan mencemari air lagi jika proyek tersebut dapat berjalan baik. Namun, terdapat beberapa hal yang perlu diperhatikan dalam sistem perpipaan pada proyek terebut.
Jaringan perpipaan dan proses pengolahan air limbah dapat optimal dengan cara perencanaan dan perhitungan yang baik sesuai dengan ketentuan teknis mengenai pengaliran air limbah dalam pipa supaya tidak terjadi endapan dan sumbatan. Dengan mengetahui kemampuan pipa-pipa utama dalam mengalirkan air limbah dari kecamatan 
Batam Kota menuju WWTP (Waste Water Treatment Plant) di Bengkong Sadai. Dan mengevaluasi hasil perbandingan perhitungan hidrolika dengan analisa perencanaan sistem perpipaan Proyek Pengembangan Sistem Saluran Air Limbah Di Pulau Batam Tahap I Kecamatan Batam Kota. Untuk mengetahui sistem perpipaan yang efektif yang dapat diterapkan di Kecamatan Batam Kota.

Air limbah domestik adalah air yang telah digunakan oleh masyarakat dan mengandung material yang ditambahkan ke air saat digunakan. Tambahan ini terdiri dari limbah yang berasal dari tubuh manusia seperti feses dan urin yang dibuang besama dengan air toilet. Selain itu air limbah domestik juga berasal dari air sisa kegiatan pencucian, kamar mandi, dapur, dan lainlain $^{[1]}$.

Air limbah domestik dibagi menjadi dua yaitu greywater dan blackwater. Greywater, pada umumnya mengacu pada air limbah yang dihasilkan dari rumah tangga dari kegiatan seperti mandi dan mencuci pakaian. Air limbah ini berbeda dengan blackwater yang terkontaminasi lebih berat dan berasal dari toilet ${ }^{[2]}$. Air limbah dan lumpur yang menumpuk pada sistem on-site rumah tangga banyak yang merembes dan mencemari tanah di sekitarnya. Hanya sejumlah kecil yang dikumpulkan dan diangkut ke IPLT oleh truk swasta yang berlisensi pemerintah ${ }^{[3]}$.

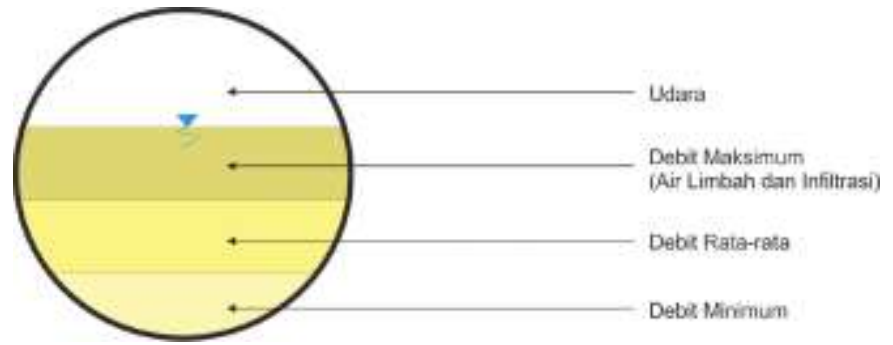

Gambar 1. Ilustrasi debit didalam pipa airan gravitasi

Aliran gravitasi merupakan salah satu metode pengaliran air limbah domestik di dalam perpipaan dengan memanfaatkan Perbedaan energi dari perbedaan elevasi antara titik hulu dan hilir pipa. Perbedaan elevasi dirancang melalui pengaturan kemiringan perpipaan sehingga air limbah domestik di dalam pipa tersebut dapat mengalir dengan kecepatan tertentu.

Perhitungan debit air limbah:

1. Debit Air Limbah Rata-Rata Harian

$\boldsymbol{Q d}=(60 \%-85 \%) x \boldsymbol{q}$ air

Dimana :

Qd = debit air limbah domestik (L/det)

$\mathrm{q}$ air $=$ kebutuhan air bersih domestik

(L/org/hr)

2. Debit Infiltrasi dan Inflow

Q inflitrasi $=($ Finf $x$ Luas Wilayah $)$

Dimana :

Q inf $=$ debit rata-rata infiltrasi (L/det)

Finf $=$ faktor infiltrasi (dari grafik)

Luas = luas area pelayanan $(\mathrm{Ha})$

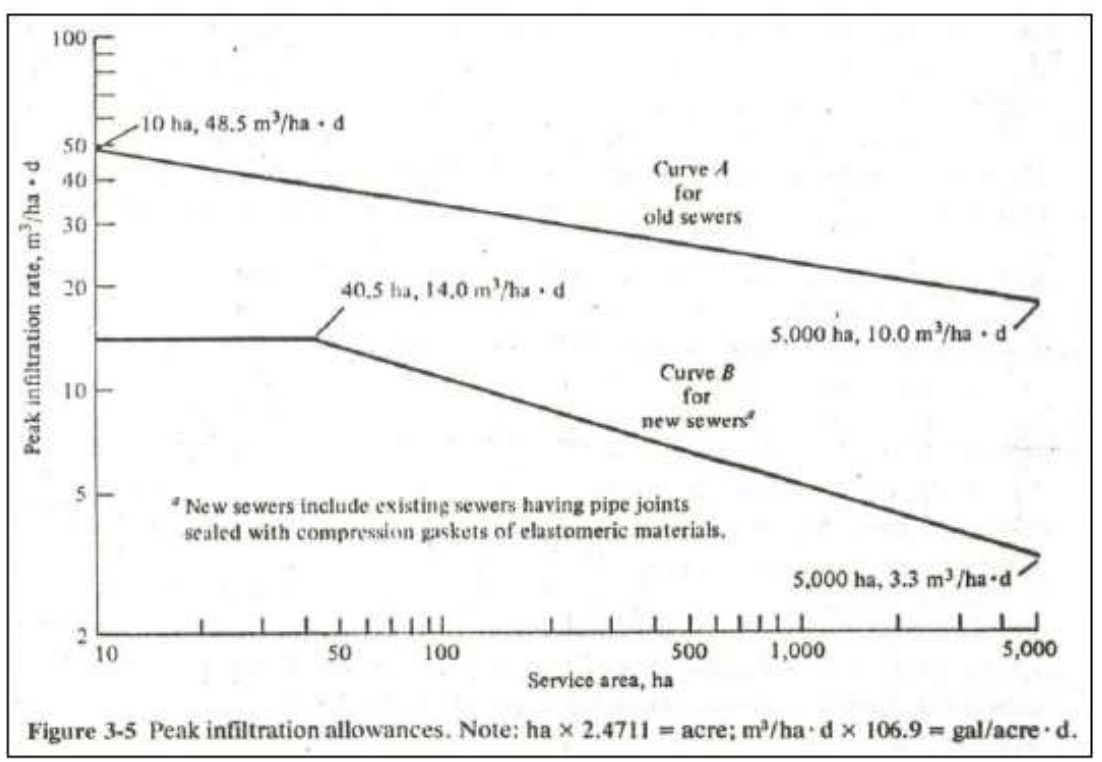

Gambar 2. Grafik Peak Infiltration Allowance 
3. Debit air limbah rata-rata (Qave)

Qave $=$ Qd + Qnd

Di mana:

Qave = debit air limbah rata-rata (L/det)

Qd = debit air limbah domestik(L/det)

Qnd = debit air limbah non domestik (L/det)

4. Debit air limbah puncak (Qpeak)

Debit puncak adalah debit air buangan yang dipergunakan dalam menghitung dimensi saluran. Debit puncak merupakan perkalian antara debit ratarata dengan faktor peak. Faktor peak dihitung sesuai dengan jumlah penduduk $^{[4]}$. Adapun penentuan faktor peak bisa dilakukan dengan persamaan sebagai berikut:
F. peak $(\mathrm{f}=(18+\sqrt{\mathrm{P}}) /(4+\sqrt{\mathrm{P}})$

Qpeak $=\mathrm{fp} \times$ Qave

Dimana:

$\mathrm{Fp} \quad=$ faktor puncak

$\mathrm{P}=$ Jumlah penduduk $/ 1000$

Qpeak = Debit puncak

Qave $\quad=$ Q rata-rata

5. Debit air limbah total (Qtot)

Qtot = Qinf + Qpeak

Di mana:

Qtot $=$ debit air limbah total $(\mathrm{L} / \mathrm{det})$

Qinf = debit infiltasi (L/det)

Qpeak = debit air limbah puncak $(\mathrm{L} / \mathrm{det})$

Diameter pipa dan kecepatan aliran diketahui melalui pembacaan nomogram manning untuk aliran penuh dan parsial dengan diketahui nilai debit terlebih dahulu.

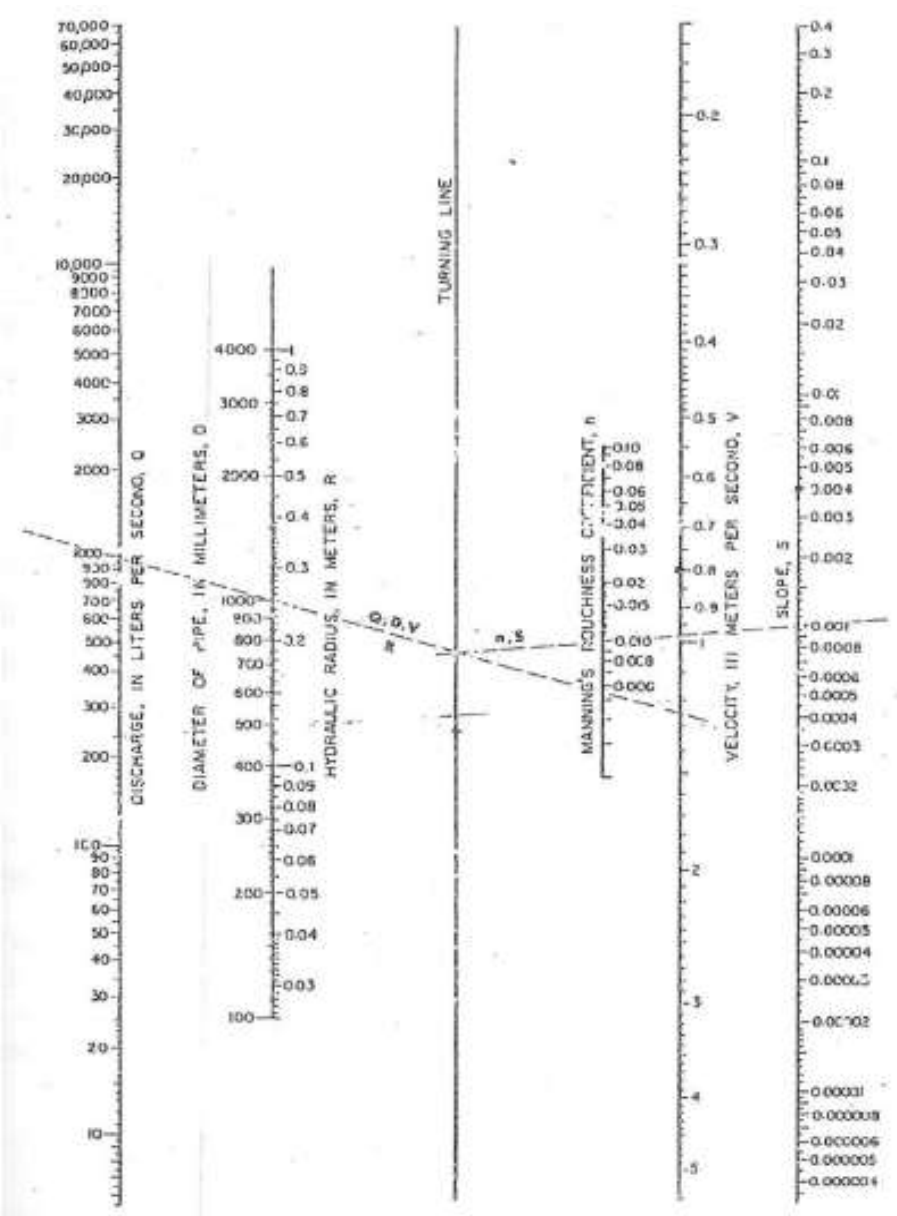

Gambar 3. Nomogram manning untuk aliran penuh pada pipa bundar dengan variasi nilai $n$ 


\section{METODE PENELITIAN}

\section{Lokasi Penelitian}

Penelitian dilakukan pada Proyek Pengembangan Sistem Saluran Air Limbah
Di Pulau Batam-Tahap I Kecamatan Batam Kota. Khususnya pipa utama yang berada di pumping station 1 yang berlokasi di kantor pengolahan air dan limbah Batam Centre.

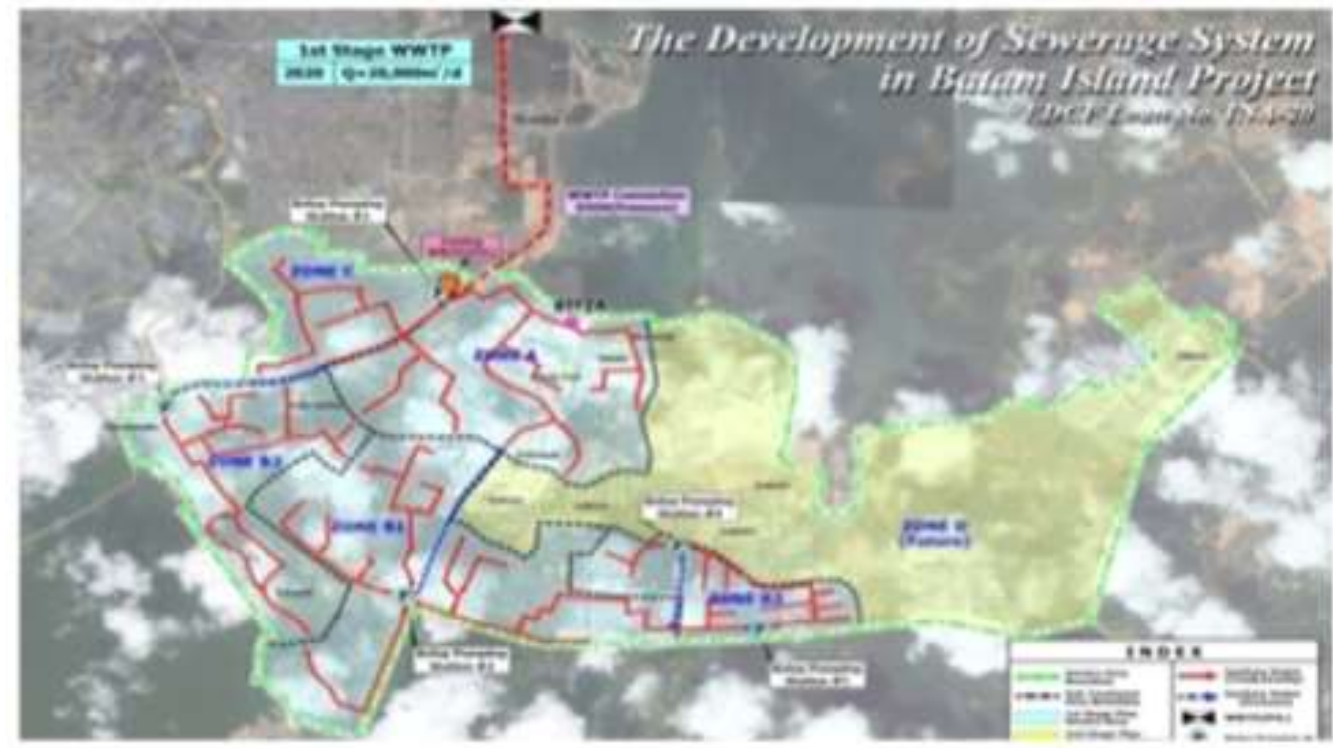

Gambar 4. Lokasi penelitian

\section{Diagram Alir Penelitian}

Penelitian ini bersifat analisa terhadap studi kasus, yaitu dengan membandingkan analisa perhitungan penulis dengan data teknis pipa utama pada Proyek Pengembangan Sistem Saluran Air Limbah Di Pulau Batam-Tahap I Kecamatan Batam Kota.

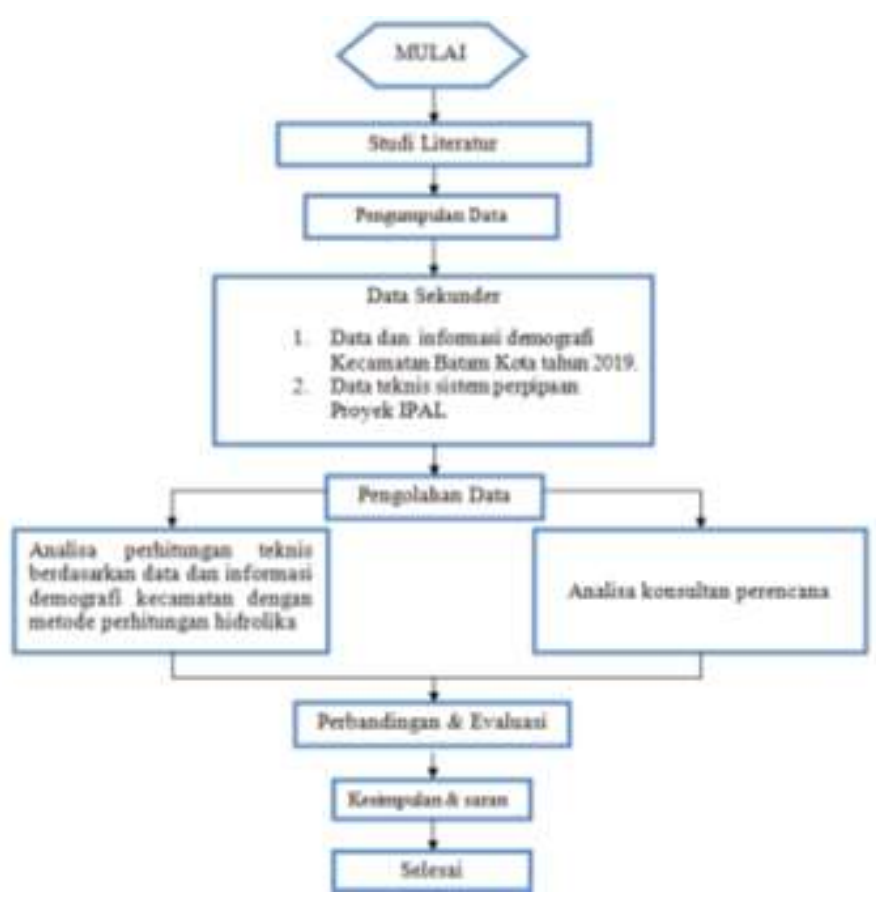

Gambar 5. Diagram alir penelitian
HASIL DAN PEMBAHASAN

Perpipaan yang digunakan

Pipa yang digunakan pada pekerjaan IPAL ini ada lah pipa khusus untuk air limbah dengan pipa GRP (Glass Fiber Reinforced Plastic) dan diambil nilai koefisien manning 0,013 berdasarkan tabel di bawah ini.

Tabel 1. Koefisien kekerasan manning

\begin{tabular}{|c|c|c|}
\hline No & Jeais Saluran & Koefisien Kekasaran Manning (in) \\
\hline \multirow{3}{*}{1} & Pea Besi Tanpa Lapisan & $0,012-0,015$ \\
\hline & Dergan Lapisan Sernen & $0,012-0,013$ \\
\hline & Pipa Disiapis Getat & $0,011-0,017$ \\
\hline 2 & Piga Astbestos Sumin & $0,010-0,015$ \\
\hline 3 & Salutan Pasangan Batu Eata & $0,012-0,017$ \\
\hline 4 & Pina Betnn & $0,012-0,016$ \\
\hline 5 & Pioa Baja Spiral dan Pipa Kelingan & $0,013-0.017$ \\
\hline 5 & Pepo Plastik Halus (PVG) & $0,002-0,012$ \\
\hline 7 & Pẹa Tanah Lat Mirifod Clyy & $0,011-0.055$ \\
\hline
\end{tabular}

\section{Perhitungan Zona A1-1}

- $\quad$ Qd

Perhitungan debit air limbah domestik yang dihasilkan oleh zona A1-1 adalah sebagai berikut: (berdasarkan perhitungan 1) Jumlah penduduk $=42093$ orang $\mathrm{Q}$ air bersih $\quad=190$ liter/orang/hari $\mathrm{Q}$ air limbah $\quad=80 \% \mathrm{Q}$ air bersih 
Qd

$$
\begin{aligned}
& =80 \% \times 190 \times 2093 \mathrm{o} \\
& =6.398 .136 \text { ltr/hari } \\
& =0,0740525 \mathrm{~m}^{3} / \text { detik }
\end{aligned}
$$

- $\quad$ Qnd

Perhitungan berdasarkan gambaran demografi dari BPS Kota Batam ${ }^{[5]}$.

$\Sigma$ Qnd $=4.201 .616 \mathrm{ltr} / \mathrm{hari}$

$$
=0,0486298 \mathrm{~m}^{3} / \mathrm{detik}
$$

- $\quad$ Q infiltrasi

Nilai faktor infiltrasi yang di dapat dari grafik Peak Infiltration Allowance adalah 6,0 $\mathrm{m}^{3} /$ ha.hari. Maka perhitungan Q infiltrasi sebagai berikut :

$$
\begin{aligned}
\text { Q inf } & =\text { Finf X Luas Wilayah } \\
& =6,0 \mathrm{~m}^{3} / \text { ha.hari X } 921 \text { ha } \\
& =5.526 \mathrm{~m}^{3} / \text { hari } \\
& =0,0639583 \mathrm{~m}^{3} / \text { detik }
\end{aligned}
$$

- $\quad$ Q rata-rata

$$
\begin{aligned}
\mathrm{Q} \text { ave } & =\mathrm{Qd}+\mathrm{Qnd} \\
= & 0,0740525 \mathrm{~m}^{3} / \mathrm{detik}+ \\
& 0,0486298 \mathrm{~m}^{3} / \text { detik }
\end{aligned}
$$

$$
=0,1226823 \mathrm{~m}^{3} / \mathrm{detik}
$$

- $\quad$ Q peak

Jumlah penduduk yang dilayani perpipaan zona A1-01 adalah 42093 jiwa. Jadi faktor puncak untuk zona A1-01 adalah:

$$
\begin{aligned}
\text { F peak } & =(18+\sqrt{P}) /(4+\sqrt{P}) \\
& =\frac{18+\sqrt{\frac{42093}{1000}}}{4+\sqrt{\frac{42093}{1000}}} \\
& =2,335
\end{aligned}
$$

Jadi, debit puncak adalah :

$$
\begin{aligned}
\mathrm{Q} \text { peak } & =\mathrm{fp} \text { X Qave } \\
& =2,335 \times 0,1226823 \mathrm{~m}^{3} / \text { detik } \\
& =0,28646 \mathrm{~m}^{3} / \mathrm{detik}
\end{aligned}
$$

- $\quad \mathrm{Q}$ total

$$
\begin{aligned}
\mathrm{Q} \text { total } & =\mathrm{Q} \text { infiltrasi }+\mathrm{Q} \text { peak } \\
& =0,0639583 \mathrm{~m}^{3} / \text { detik }+ \\
& 0,28646 \mathrm{~m}^{3} / \text { detik } \\
= & 0,350418 \mathrm{~m}^{3} / \text { detik }
\end{aligned}
$$

- $\quad$ Nomogram manning

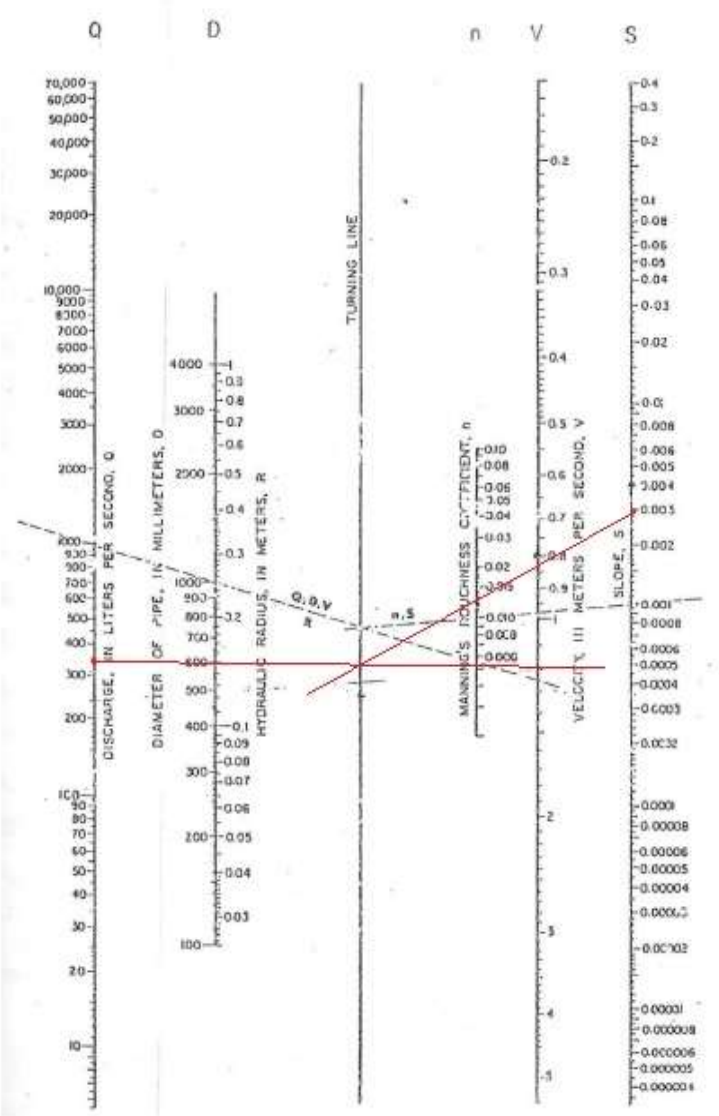

Gambar 6. Nomogram manning untuk zona A1-1 
Berdasarkan nomogram manning didapatkan diameter pipa yang bisa di gunakan untuk zona A1-1 adalah berdiameter $600 \mathrm{~mm}$. Dan untuk perhitungan diameter pipa dan kecepatan aliran dari nomogram di atas adalah :

$$
\begin{aligned}
& \mathrm{Q}=\frac{0,3117}{n} \times D^{\frac{8}{3}} \times S^{\frac{1}{2}} \\
& 0,344 \quad=\frac{0,3117}{0,013} \times D^{\frac{8}{3}} \times 0,003^{\frac{1}{2}} \\
& \mathrm{D}=605 \mathrm{~mm}
\end{aligned}
$$

Digunakan pipa dengan ukuran 700mm.

$$
\begin{array}{ll}
\text { Vf } & =1,2 \mathrm{~m} / \text { detik } \\
\text { Maka, } & \\
\text { Vp } & =1,2 \mathrm{~m} / \operatorname{detik} \text { X } 1,16 \\
& =1,392 \mathrm{~m} / \operatorname{detik}(\mathrm{OK})
\end{array}
$$

\section{Perhitungan Zona A2-1}

- $\quad$ Qd

Perhitungan debit air limbah domestik yang dihasilkan oleh zona A2-1 adalah sebagai berikut: (berdasarkan perhitungan 1)

$$
\begin{array}{ll}
\text { Jumlah penduduk } & =60666 \text { orang } \\
\text { Q air bersih } & =190 \text { liter/orang/hari } \\
\text { Q air limbah } & =80 \% \text { Q air bersih } \\
\text { Qd } & =80 \% \times 190 \times 60666 \\
& =9.221 .232 \text { ltr } / \text { hari } \\
& =0,106727 \mathrm{~m}^{3} / \text { detik }
\end{array}
$$

\section{- $\quad$ Qnd}

$$
\begin{aligned}
& \text { Perhitungan berdasarkan gambaran } \\
& \text { demografi dari BPS Kota Batam }{ }^{[5]} \text {. } \\
& \begin{aligned}
\sum \text { Qnd } & =6.301 .400 \mathrm{ltr} / \mathrm{hari} \\
& =0,0729329 \mathrm{~m}^{3} / \text { detik }
\end{aligned}
\end{aligned}
$$

- Q infiltrasi

Maka nilai faktor infiltrasi yang di dapat dari grafik Peak Infiltration Allowance adalah $5,0 \mathrm{~m}^{3} /$ ha.hari. Maka perhitungan $\mathrm{Q}$ infiltrasi sebagai berikut :

$$
\begin{aligned}
\text { Q inf } & =\text { Finf X Luas area } \\
& =5,0 \mathrm{~m}^{3} / \mathrm{ha} \cdot \text { hari X } 1207 \text { ha } \\
& =6035 \mathrm{~m}^{3} / \text { hari } \\
& =0,0698495 \mathrm{~m}^{3} / \text { detik }
\end{aligned}
$$

- Q rata-rata

$$
\begin{aligned}
\mathrm{Q} \text { ave } & =\mathrm{Qd}+\text { Qnd } \\
& =0,106727 \mathrm{~m}^{3} / \text { detik }+ \\
& 0,0729329 \mathrm{~m}^{3} / \text { detik } \\
& =0,1796599 \mathrm{~m}^{3} / \text { detik }
\end{aligned}
$$

- Qpeak

Jumlah penduduk yang dilayani perpipaan zona A2-01 adalah 60666 jiwa. Jadi faktor puncak untuk zona A2-01 adalah:

$$
\begin{aligned}
\text { F peak } & =(18+\sqrt{P}) /(4+\sqrt{P}) \\
& =\frac{18+\sqrt{\frac{60666}{1000}}}{4+\sqrt{\frac{60666}{1000}}} \\
& =2,188
\end{aligned}
$$

Jadi, debit puncak adalah :

$$
\begin{aligned}
\text { Q peak } & =\mathrm{fp} \text { X Qave } \\
& =2,188 \text { X } 0,1796599 \mathrm{~m}^{3} / \text { detik } \\
& =0,393095 \mathrm{~m}^{3} / \text { detik }
\end{aligned}
$$

- $\quad$ Q total

$$
\begin{aligned}
\mathrm{Q} \text { total } & =\mathrm{Q} \text { infiltrasi }+\mathrm{Q} \text { peak } \\
& =0,0698495 \mathrm{~m}^{3} / \text { detik }+ \\
& 0,393095 \mathrm{~m}^{3} / \text { detik } \\
& =0,4629445 \mathrm{~m}^{3} / \text { detik }
\end{aligned}
$$


- $\quad$ Nomogram manning

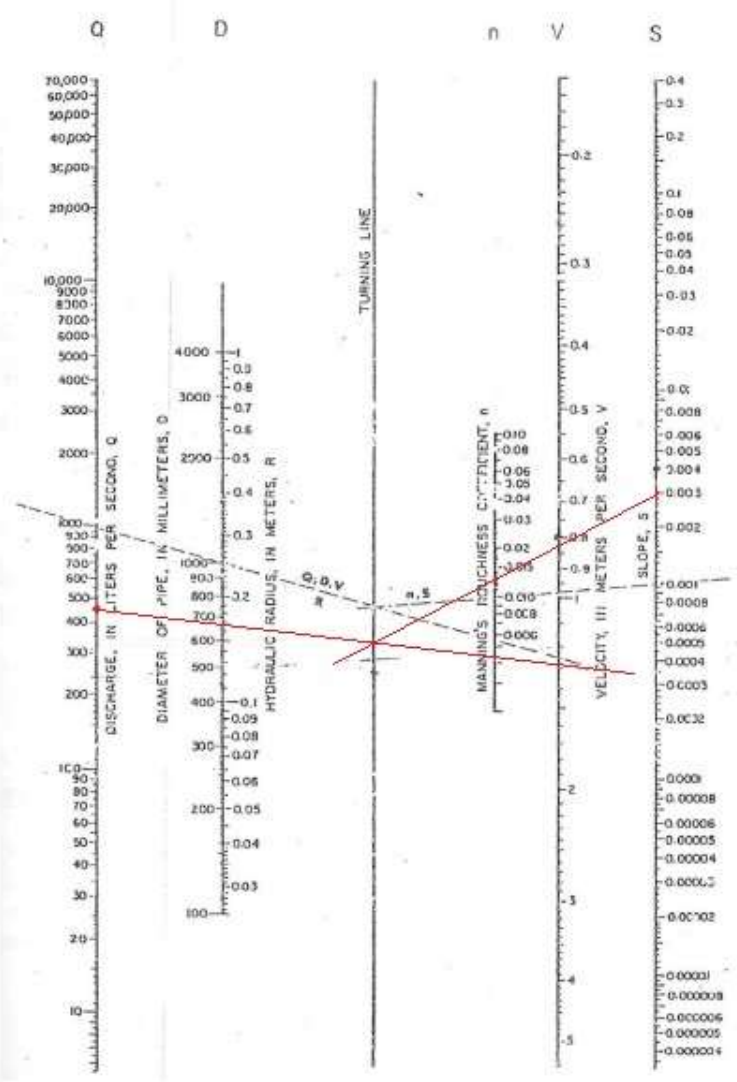

Gambar 7. Nomogram manning untuk zona A2-1

$\mathrm{Q} \quad=\frac{0,3117}{n} \times D^{\frac{8}{3}} \times S^{\frac{1}{2}}$

$0,454=\frac{0,3117}{0,013} \times D^{\frac{8}{3}} \times 0,003^{\frac{1}{2}}$

$\mathrm{D} \quad=672 \mathrm{~mm}$

Digunakan pipa dengan ukuran $700 \mathrm{~mm}$.

Vf $\quad=1,3 \mathrm{~m} /$ detik

Maka,

$\mathrm{Vp} \quad=1,3 \mathrm{~m} / \operatorname{detik} \times 1,16$

$=1,508 \mathrm{~m} / \operatorname{detik}(\mathrm{OK})$

\section{Hasil Evaluasi Perbandingan Perhitungan Hidrolika}

Dari hasil perhitungan hidrolika di atas terdapat beberapa perbedaan pada diameter pipa yang digunakan. Berikut adalah perbedaan yang digunakan pada sistem perpipaan antara hitungan hidrolika pada penelitian ini dengan perencanaan sistem perpipaan IPAL di Kecamatan Batam Kota:
Tabel 2. Perbandingan analisa diameter pipa

\begin{tabular}{|c|c|c|c|c|}
\hline \multirow{3}{*}{ ANALISA } & \multicolumn{2}{|c|}{ SLOPE } & \multicolumn{2}{|c|}{$\begin{array}{l}\text { DIAMEIER } \\
\text { (mm) }\end{array}$} \\
\hline & ZONA & $20 N \mathrm{~A}$ & $20 \mathrm{NA}$ & $20 \mathrm{NA}$ \\
\hline & A1-1 & A2:2 & Al:1 & A 2.2 \\
\hline PERHITUNGAN HIDROLIKA & $0,3 \%$ & 0,396 & 700 & 700 \\
\hline PERENCANAANIPAL & 0,29 & 0.1796 & 600 & 700 \\
\hline KECAMATANBATAMKOTA & & & & \\
\hline
\end{tabular}

\section{KESIMPULAN}

1. Jumlah debit total pada sistem perpipaan IPAL di Kecamatan Batam Kota pada zona A1-1 adalah $0,350418 \mathrm{~m}^{3} /$ detik dan pada zona A2-1 adalah $0,4629445 \mathrm{~m}^{3} /$ detik. Sehingga diameter pipa yang dibutuhkan dengan slope pipa $0,3 \%$ berdasarkan nomogram manning pada zona A1-1 dan zona A2-1 menggunakan pipa dengan diameter 700mm. Sedangkan, diameter yang digunakan pada perencanaan Proyek IPAL pada zona A1-1 adalah $600 \mathrm{~mm}$ dengan slope 0,17\% dan A2-1 $700 \mathrm{~mm}$ 
dengan slope 0,2\%. Pada penggunaan manhole dengan diameter $700 \mathrm{~mm}$ digunakan jarak manhole 125-150 m sedangkan pada perencanaan Proyek IPAL digunakan jarak rata-rata $60 \mathrm{~m}$.

2. Berdasarkan perhitungan hidrolika penulis, pipa yang digunakan pada zona A1-1 dengan diameter $600 \mathrm{~mm}$ belum mencukupi untuk melayani debit limbah yang diterima pada zona ini. Dan diameter pipa untuk zona A2-1 dengan diameter $700 \mathrm{~mm}$ sudah mencukupi untuk melayani debit air limbah yang diterima.

3. Sistem perpipaan akan efektif dengan melakukan studi kelayakan terhadap berbagai aspek pekerjaan, melakukan penyusunan master plan yang efektif dan efisien, dan juga penggunaan dan penempatan bangunan dan aksesoris pelengkap. Sehingga, sistem perpipaan air limbah di Kecamatan Batam Kota dapat berjalan sesuai dengan kelayakan teknis yang sudah direncanakan. Selain itu, dapat disimpulkan pada sistem perpipaan untuk penggunaan nomogram manning jika slope diperbesar maka diameter pipa menjadi kecil namun galian pipa di dalam tanah akan semakin dalam. Begitu juga sebaliknya jika slope diperkecil maka diameter pipa semakin besar namun galian untuk pipa semakin dangkal. Namun, tetap harus mempertimbangkan kecepatan aliran air limbah $\left(0,6 \mathrm{~m}^{3} /\right.$ detik $-2,5 \mathrm{~m}^{3} /$ detik $)$

\section{SARAN}

1. Dalam perhitungan sistem perpipaan harus dipertimbangkan segala aspek dari limbah domestik dan non domestik, infiltrasi pada pipa, slope pipa, dan kecepatan aliran pada pipa.
2. Untuk masyarakat wajib meningkatkan kesadaran untuk memperhatikan lingkungan khususnya tidak membuang limbah sembarangan dan memiliki sistem pembuangan septic tank yang baik agar sistem perpipaan juga dapat terjaga dari sampah-sampah dan kotoran yang tidak seharusnya ada didalam pipa.

3. Saran untuk peneliti selanjutnya agar dapat melanjutkan penelitian ini karena masih banyak kekurangan yang penulis rasakan di dalam penelitian ini.

\section{REFERENSI}

[1] Mara, D. Ducan, 2003, Domestic Wastewater Treatment in Developing Countries, New York.

[2] Allen, L., Juliet C. S., Meena, P., 2010, Overview of Greywater Reuse: The Potential of Greywater Systems to Aid Sustainable Water Management, California, Pacific Institute.

[3] Winters, M. S., Abdul, G. K., Berly M., 2014, Public Service Provision Under Condition of Insufficient Citizen Demand: Insight from The Urban Sanitation Sector in Indonesia, World Development, 60, 31-42.

[4] Fair, G. M., Gayer, J. C., 1968, Water and Wastewater Engineering: Water Purification and Wastewater Treatment and Disposal v2, New York, John Wiley \& Sons Inc.

[5] Badan Pusat Statistika, 2019, Kecamatan Batam Kota dalam Angka 2019, Batam, BPS Kota Batam. 